\title{
ACESSIBILIDADE ESPACIAL EM INSTITUIÇÕES DE LONGA PERMANÊNCIA PARA O IDOSO - ILPI: O CASO DA COMPONENTE ESPACIAL DESLOCAMENTO
}

\author{
OLIVEIRA, Gabriela Bastos de (1); \\ LOPES, Aline Cesa de Sousa (2) \\ (1) Centro Universitário Estácio de Santa Catarina, mestre \\ e-mail:gabriela.bastosara@gmail.com \\ (2) Centro Universitário Estácio de Santa Catarina, mestre \\ e-mail:alinecesa@gmail.com
}

\begin{abstract}
RESUMO
A pesquisa de caráter qualitativo consiste em analisar as condições de acessibilidade de um grupo de idosos em uma Instituição de Longa Permanência para Idosos (ILPI), concentrando-se na componente de Acessibilidade Espacial: deslocamento. Para tanto, fez-se uso de diferentes métodos, tais como pesquisa bibliográfica, observações e entrevistas. A partir deste processo, constatou-se que os espaços adaptados desta instituição não só apresentam problemas de acessibilidade para o idoso, como também prejudicam a realização de algumas atividades para qualquer pessoa. Por fim, algumas soluções foram propostas para possibilitar conforto e segurança ao idoso pensando na sua qualidade de vida.
\end{abstract}

Palavras chave: instituição de longa permanência para idosos; acessibilidade espacial; idoso.

\begin{abstract}
The qualitative study is to analyze in a elderly people in long-term institutions, focusing on the Accessibility Spatial component: displacement. For this, it was used different methods such as bibliographic research, exploratory visits and interviews. For this, it was using different methods such as literature, observations and interviews. From this process, it was found that the adapted spaces of this institution not only have accessibility problems for the elderly, but also hampers the realization of some activities for everyone. Finally, some solutions have been developed to allow for comfort and security to the elderly thinking about their quality of life.
\end{abstract}

Keywords: elderly people in long-term institutions; accessibility spatial; elderly.

\section{INTRODUÇÃO}

Para a Organização Mundial da Saúde (OMS), idoso é a pessoa com idade igual ou superior a 60 anos. No Brasil, de acordo com dados do Instituto Brasileiro de Geografia e Estatística (IBGE, 2010), a parcela da população idosa no período de 1999 a 2009 passou de 9,1\% para $11,3 \%$. O aumento da expectativa de vida da população brasileira representa um grande desafio não só para as políticas públicas, mas para a sociedade como um todo, uma vez que essa parcela da população convive frequentemente com a redução de suas capacidades funcionais e necessitam de cuidados especiais. 


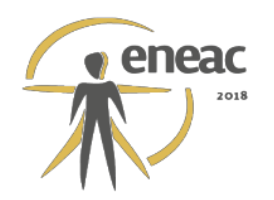

Sabe-se que os idosos, devido ao processo de envelhecimento, apresentam limitações que implicam em necessidades diferenciadas. No caso do espaço construído, estas limitações influenciam na interação deste usuário com o ambiente perante o desenvolvimento de suas atividades, como, por exemplo, subir ou descer degraus devido a problemas de equilíbrio. No entanto, é importante ressaltar que o processo de envelhecimento não deve ser fator gerador de empecilhos para que idosos desenvolvam suas atividades diárias de forma segura e confortável, sejam estas de higiene, lazer, convívio social.

O Estatuto do Idoso (BRASIL, 2003) orienta que os programas de assistência à pessoa idosa devem ser executados, de preferência, em seus lares, no entanto, cada vez mais famílias buscam as Instituições de Longa Permanência para Idosos (ILPI), ou seja, moradias especializadas que contam com sistema contínuo de cuidados.

Conforme o regulamento técnico para o funcionamento das instituições residenciais sob sistema participativo e de longa permanência para idosos (ANVISA, 2005), a infraestrutura física das ILPls deve manter requisitos mínimos exigidos em códigos, leis ou normas pertinentes em diferentes esferas: federal, estadual ou municipal, além de normas especificas da Associação Brasileira de Normas Técnicas (ABNT).

Diante do exposto, a presente pesquisa consiste em conhecer as mudanças fisiológicas, bem como as limitações ocorridas com o processo de envelhecimento que possam influenciar no uso dos espaços de ILPI, identificar as componentes de acessibilidade espacial, com intuito de propor soluções para possibilitar conforto e segurança ao idoso. Ressalta-se que, pela maior prevalência de problemas como ausência de espaços de circulação e de áreas para manobras, localização de mobiliários e equipamentos que prejudicam a realização de atividades com conforto e independência, o artigo se ateve a componente de acessibilidade espacial Deslocamento.

A necessidade de realização desta pesquisa justifica-se pela importância da arquitetura na concepção de espaços que visam contribuir para as necessidades da população idosa, parcela da população que segue uma linha ascendente de aumento no país. Aliado a isto, considerando a revisão da ABNT NBR 9050 em 2015, constatou-se a ausência de reformulações na legislação referente às ILPI, fato constatado no ambiente construído analisado nesta pesquisa.

\section{METODOLOGIA}

A pesquisa desenvolveu-se a partir da abordagem qualitativa. Os métodos qualitativos estudam situações de vida e textos de cunho social, que apresentam fenômenos subjetivos, tais como dados históricos, expressões de crenças, valores, expectativas, motivações, conhecimentos, percepções, sentimentos, queixas, emoções e práticas, com o intuito de descrição, interpretação e explicação de uma dada realidade sem a preocupação de quantificação e generalização dos resultados (BOGDAN; BIKLEN, 1994; MINAYO et al., 2004).

Este trabalho configura-se em uma pesquisa descritiva. Pela sua natureza, pode ser identificada como estudo de caso, segundo alguns aspectos definidos por Bogdan e Biklen (1994), como ser realizada sobre um contexto, em um período de tempo determinado.

Como técnicas para coleta de dados têm-se: pesquisas bibliográficas, documentais e imagéticas como base teórica para a coleta de informações no estudo de caso. Já as técnicas utilizadas no trabalho de campo são: visitas exploratórias; observação não participante com o objetivo de compreender e avaliar a relação idoso $x$ ambiente $x$ atividades e, para isto, adaptou-se uma planilha desenvolvida por Silva (1982), a qual contém um programa de necessidades básico e a caracterização das funções primordiais a serem atendidas pela 


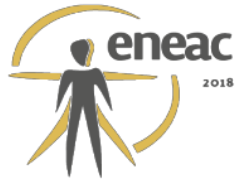

habitação; leituras espaciais e entrevista aberta, esta efetuada com os funcionários devido ao déficit cognitivo e disfunção funcional que acomete os idosos da ILPI em estudo. Entende-se que as funções desempenhadas pelos funcionários, por auxiliarem os idosos nas suas atividades e necessidades diárias, os qualificam como seus porta-vozes neste estudo.

\section{REFERECIAL TEÓRICO}

O ser humano sempre se preocupou com o envelhecimento, porém, este assunto é encarado de forma muito heterogênea. Algumas pessoas caracterizam este processo como uma diminuição geral das capacidades da vida diária, outras o consideram como um período de crescente vulnerabilidade, fator que implica na maior dependência do núcleo familiar devido as restrições advindas do processo de envelhecimento.

A restrição indica o grau de dificuldade que cada indivíduo possui para realizar alguma atividade, e é um termo utilizado pela Organização Mundial da Saúde (WHO, 2002). Os tipos de restrições classificam-se:

- Restrição sensorial: refere-se às dificuldades na percepção das informações do meio ambiente devido a limitações nos sistemas sensoriais (auditivo, visual, paladar/olfato e orientação).

- Restrição cognitiva: refere-se às dificuldades no tratamento das informações recebidas (atividades mentais) ou na sua comunicação através de produção linguística devido a limitações no sistema cognitivo.

- Restrição físico-motora: refere-se ao impedimento, ou às dificuldades encontradas em relação ao desenvolvimento de atividades que dependam de força física, coordenação motora, precisão ou mobilidade.

- Restrições múltiplas: decorrem da associação de mais de um tipo de restrição de natureza diversa.

Contudo, é sabido que o processo de envelhecimento impacta na interação entre o idoso, suas atividades e o espaço em que habita. Sendo assim, é dever da ILPI "manter padrões de habitação compatíveis com as necessidades deles, bem como provê-los com alimentação regular e higiene indispensáveis às normas sanitárias e com estas condizentes, sob as penas da lei" (BRASIL, 2003).

Os parâmetros abordados nesta pesquisa para categorizar estas necessidades dividem-se em três grupos, segundo classificação proposta por Hunt (1991, p.130): as necessidades físicas, as informativas e as sociais. Ressalta-se que, juntamente à esta classificação, serão incluídas as quatro componentes da acessibilidade, em sua totalidade, que são, segundo Dischinger, Bins Ely e Piardi (2009): Orientação Espacial; A Comunicação; O Deslocamento; O Uso. Para Bins Ely (2009), o termo acessibilidade pressupõe ausência de diferentes e quaisquer barreiras, o que permite a inclusão social e o deslocamento seguro e independente de qualquer cidadão.

- Necessidades físicas - As necessidades físicas são aquelas que asseguram a manutenção da saúde física e os níveis de conforto (HUNT,1991).

Compartilhando deste entendimento, a componente de acessibilidade Deslocamento garante a execução das atividades relacionadas ao ambiente, e faz referência às condições de deslocamento ao longo de percursos horizontais e verticais de forma independente, segura e confortável, sem interrupções e livre de barreiras.

- Necessidades informativas - As necessidades informativas estão relacionadas ao modo como a informação sobre o ambiente é processada. Hunt (1991) identifica dois aspectos principais para a informação ser processada: a percepção, que é o processo 


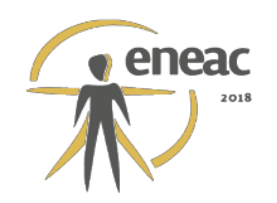

de obter ou receber a informação do ambiente; e a cognição, que representa como a pessoa organiza e relembra a informação recebida do ambiente.

Para compor esta categoria, as componentes de acessibilidade Orientação espacial e Comunicação garantem a execução das atividades relacionadas ao ambiente. A Orientação Espacial é ligada à compreensão do espaço, permitindo assim, que os usuários reconheçam a identidade de funções do ambiente interno ou externo e desta forma definam suas estratégias de deslocamento e uso. Já a Comunicação refere-se às possibilidades de troca de informações interpessoais, ou troca de informações por meio da utilização de equipamentos de tecnologia assistiva, que permitam o acesso, a compreensão e o uso das atividades existentes.

- Necessidades sociais - As necessidades sociais estão relacionadas com a promoção do controle da privacidade e/ou interação social.

A componente de acessibilidade Uso, possibilidade de participação de todo e qualquer indivíduo nas atividades, podendo utilizar todos os ambientes e equipamentos, promove a concretização desta necessidade, porém, é importante destacar que as demais componentes espaciais (Orientação espacial; Deslocamento; Comunicação) são premissas indispensáveis para interação entre os usuários.

Para as ILPI, Bins Ely (2009) acrescenta que as soluções arquitetônicas são mais complexas, pois devem atender às necessidades dos idosos institucionalizados, bem como às dos seus cuidadores, que os auxiliam a cumprir suas necessidades básicas ou tarefas habituais. Diante disto, um fator importante a ser considerado no projeto arquitetônicos destinados à ILPI são ambientes espacialmente acessíveis. A norma ABNT NBR 9050/2015 trata da acessibilidade em edificações, mobiliário, espaços e equipamentos urbanos, e deve ser aplicada a todos os projetos que virem a ser elaborados, construídos, bem como as reformas e ampliações de edificações e equipamentos já existentes. Ressalta-se que a análise e discussão dos resultados a seguir serão embasados na Norma acima citada.

\section{ANÁLISE DO AMBIENTE E DISCUSSÃO DOS RESULTADOS}

Com intuito de organizar e permitir a melhor compreensão do estudo, apresenta-se a seguir o ambiente em análise, o perfil dos usuários, bem como os resultados encontrados e propostas sugeridas.

\subsection{O ambiente construído}

Nome da ILPI: Girassóis Residencial para idosos.

Endereço: Rua João da Silva, $n^{\circ} 473$, bairro Ipiranga, cidade de São José em Santa Catarina. O município de São José, localizado na Grande Florianópolis, é o quarto mais antigo de Santa Catarina e, de acordo com os dados do IBGE (2010), a população de idosos supera a marca de 19.000 pessoas.

Quantidade de funcionários: 8 funcionários (divididos em 3 cuidadores, 1 cozinheira, 1 médico, 1 fisioterapeuta, 1 nutricionista, 1 faxineira).

O Girassóis Residencial para idosos está locado em uma residência alugada, abrangendo uma área total de aproximadamente $222,00 \mathrm{~m} 2$, distribuídos entre a casa e o anexo térreos (Figura 1). A casa, com 130,00 m2 de área total construída, engloba área de estar, jantar, 5 dormitórios (sendo uma suíte) e um banheiro social. O anexo abriga as áreas de serviço, cozinha, refeitório e depósito. Ressalta-se a existência de área externa de lazer. 


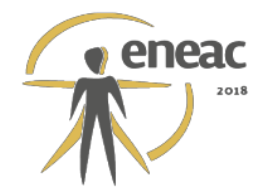

Para este artigo, as soluções propostas foram apresentadas através do recorte de uma pesquisa maior, com intuito de que os problemas identificados pudessem ser resolvidos. Assim, a componente espacial Deslocamento será analisada nos seguintes ambientes: área de acesso, área de lazer externa e suíte. A escolha destes ambientes justifica-se pela maior incidência de problemas quanto à componente em estudo.

É importante salientar que o Girassóis Residencial necessitou adaptar o espaço de forma a permitir, quando possível, o conforto e segurança dos idosos. No entanto, por se tratar de um imóvel alugado, muitos são os obstáculos oriundos destas adaptações.

Figura 1 - Planta esquemática Residencial Girassóis (sem escala).

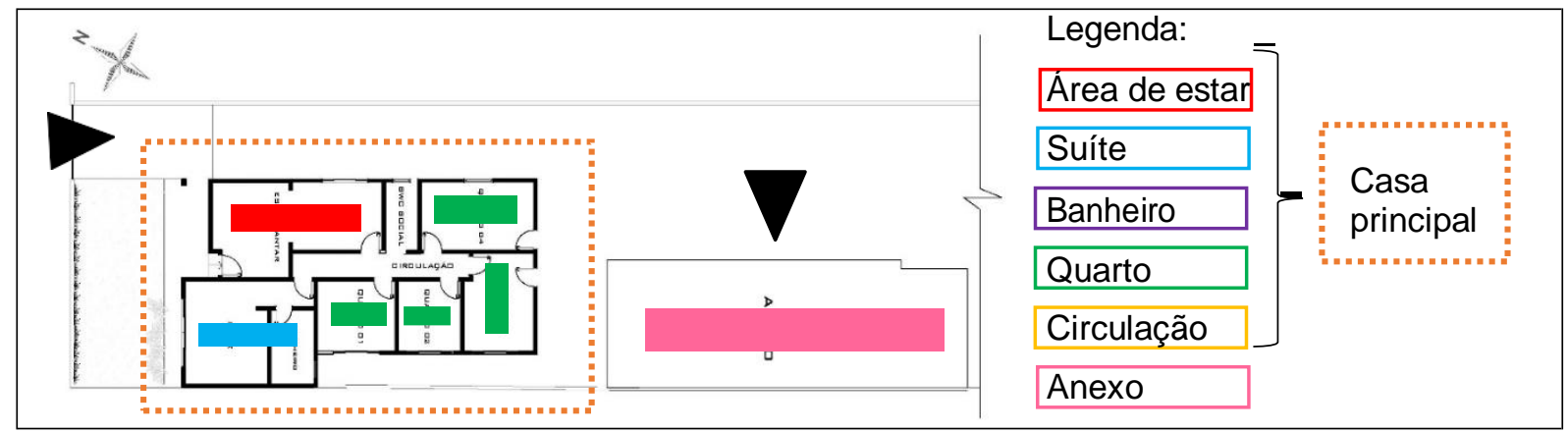

Fonte: Autoras, 2018.

\subsection{Características dos usuários}

O Girassóis Residencial abriga 11 idosos, divididos entre 5 mulheres e 6 homens, com faixa etária entre 60 a 101 anos. Cada um dos usuários possui um ou mais tipos de restrições (Tabela 1).

Tabela 1 - Restrições dos usuários

\begin{tabular}{|c|c|}
\hline Tipos de restrições & Número de internos \\
\hline Restrição sensorial & 4 \\
\hline Restrição cognitiva & 4 \\
\hline Restrição físico-motoras & 8 \\
\hline Restrições múltiplas & 5 \\
\hline
\end{tabular}

Fonte: Autoras, 2018.

Após análise do perfil dos usuários, bem como das entrevistas realizadas com os funcionários, as dificuldades encontradas para o uso da cadeira de rodas, seja como meio de locomoção permanente ou como forma de auxílio nas atividades como, por exemplo, o banho, é uma ação que encontra muitos obstáculos. 


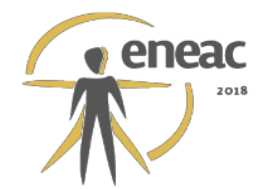

\subsection{Resultados}

Os quadros a seguir, divididos em três colunas, organizam respectivamente: os principais ambientes de uma habitação, as atividades realizadas e os problemas de deslocamento observados em planta nestes espaços. A seguir, na forma de imagem e texto, detalha-se cada problema encontrado e, após isto, são propostas pequenas adequações baseadas na NBR 9050/2015 de forma a possibilitar qualidade de vida para os usuários.

\section{Quadro 1 - Entrar e sair da ILPI - Área externa x Área interna.}

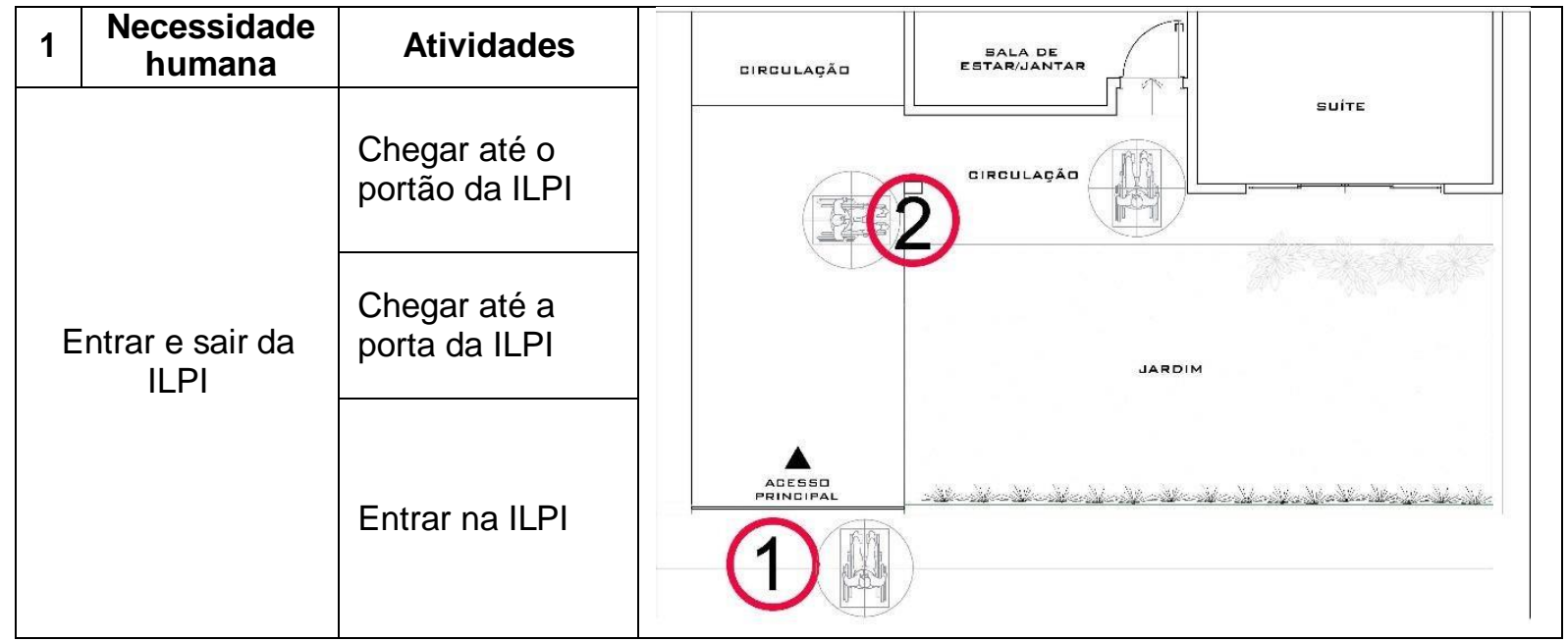

Fonte: Autoras, 2018.

- Problema 1: Para chegar até o portão de entrada ao terreno da ILPI, o usuário cadeirante utiliza a calçada (Figura 2) externa ao residencial que apresenta desnível em relação ao meio fio, além disto, a calçada possui piso em mau estado de conservação.

Figura 2 - Entrar na ILPI.

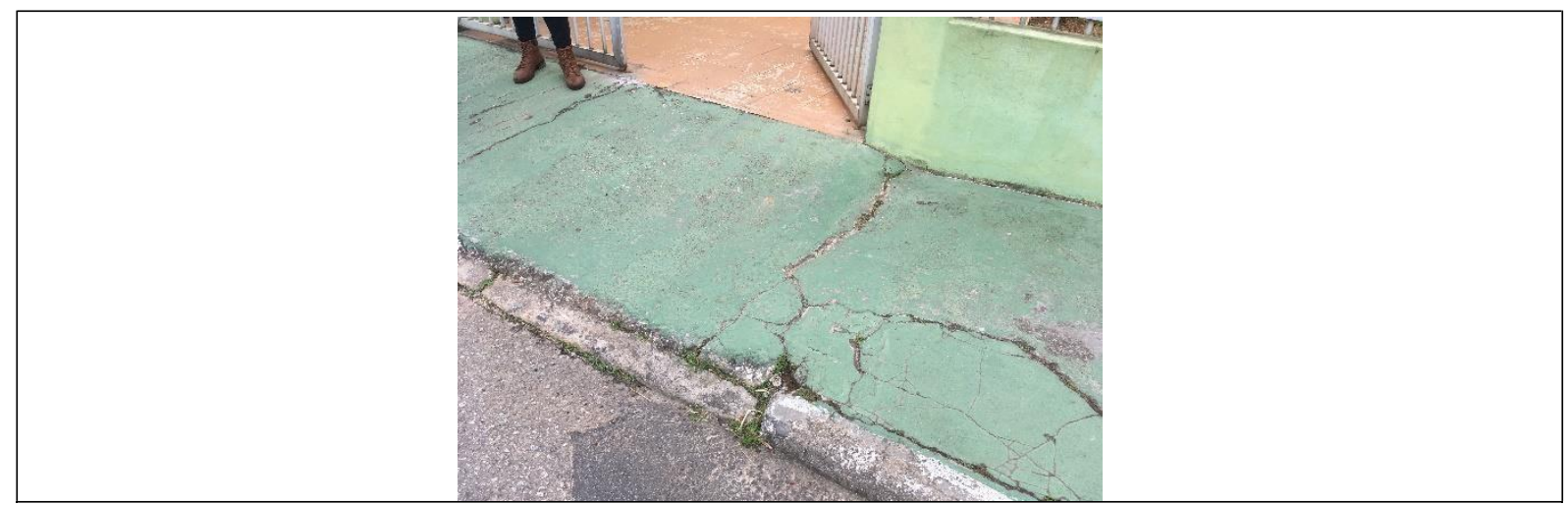

Fonte: Autoras, 2018.

Sabe-se que a calçada deve possuir revestimentos antiderrapantes, estáveis e contínuos. Deve-se prever rebaixamento do meio fio e, este rebaixo, deve estar no mínimo a $1 \mathrm{~m}$ de distância de muros e edificações além de ter desnível inferior a $1,5 \mathrm{~cm}$, de acordo com a NBR 9050/2015. 


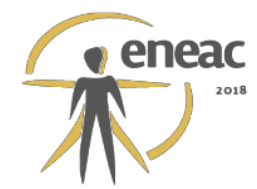

- Problema 2: A circulação junto a área de jardim até a entrada principal da ILPI possui desnível (Figura 3) que impede a passagem livre do cadeirante. A borda da circulação não apresenta proteção para a roda da cadeira, o que poderia causar acidentes, já que há um desnível de $20 \mathrm{~cm}$ entre a circulação e o espaço do jardim.

Figura 3 - Chegar até a porta de entrada da ILPI.

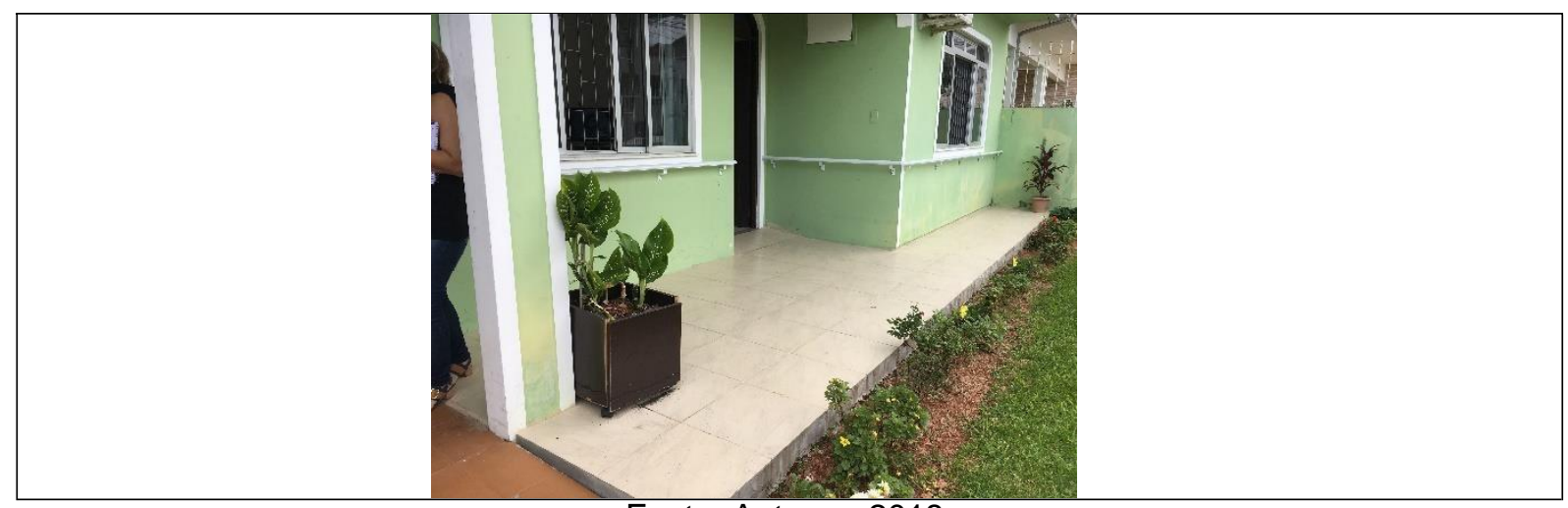

Fonte: Autoras, 2018.

Neste caso, recomenda-se a execução de patamar nivelado permitindo a livre passagem no espaço anterior e posterior ao pilar e, com a existência de desnível, mesmo que este não seja superior aos $60 \mathrm{~cm}$ especificados pela NBR9050/2015, sugere-se a execução de proteção vertical de no mínimo $0,15 \mathrm{~m}$ de altura, com a superfície de topo com contraste visual.

Quadro 2 - Lazer - Área externa.

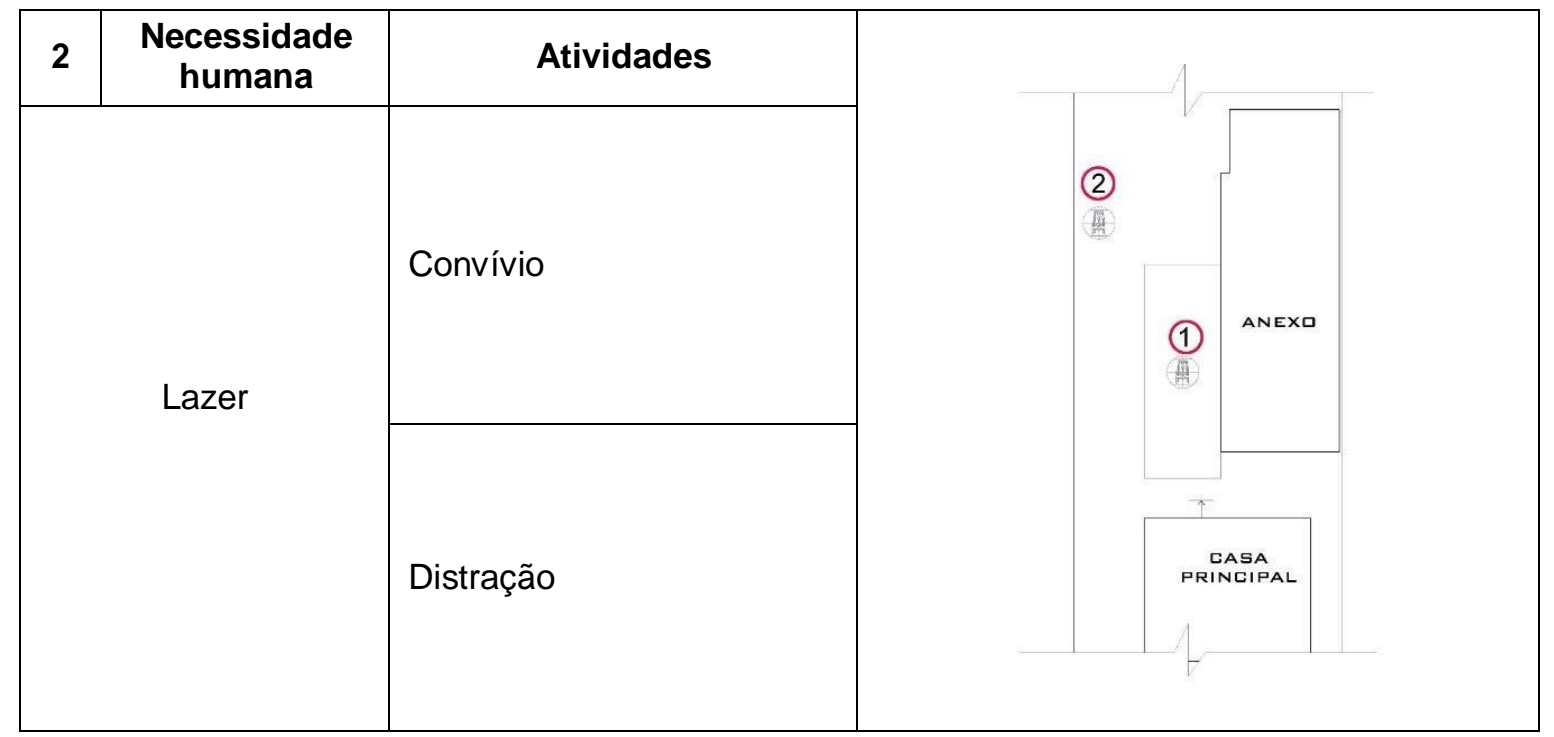

Fonte: Autoras, 2018.

- Problema 1: O lazer é uma atividade importante, pois garante que experiências de vida e o convívio entre os residentes proporcionem bem-estar social. Porém, na ILPI em estudo, a área externa de lazer corresponde a um espaço perigoso para o cadeirante devido ao piso não antiderrapante empregado, além dos desníveis através de espaços com brita e grama (Figura 4). 


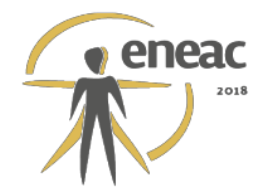

Figura 4 - Desníveis no piso da área externa de lazer.

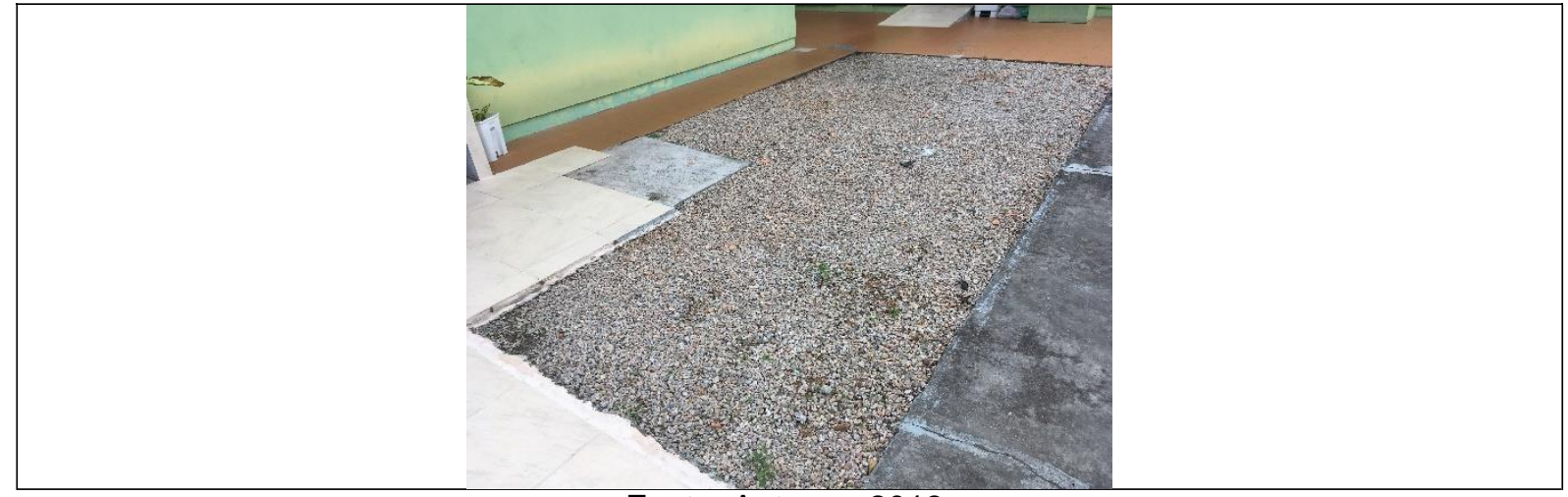

Fonte: Autoras, 2018.

- Problema 2: Constatou-se a presença de corrimão em uma parte do percurso externo, no entanto, este não é contínuo, e foi possível observar a presença de obstáculos que comprometem o deslocamento (Figura 5).

Figura 5 - Obstáculos no percurso área de lazer.

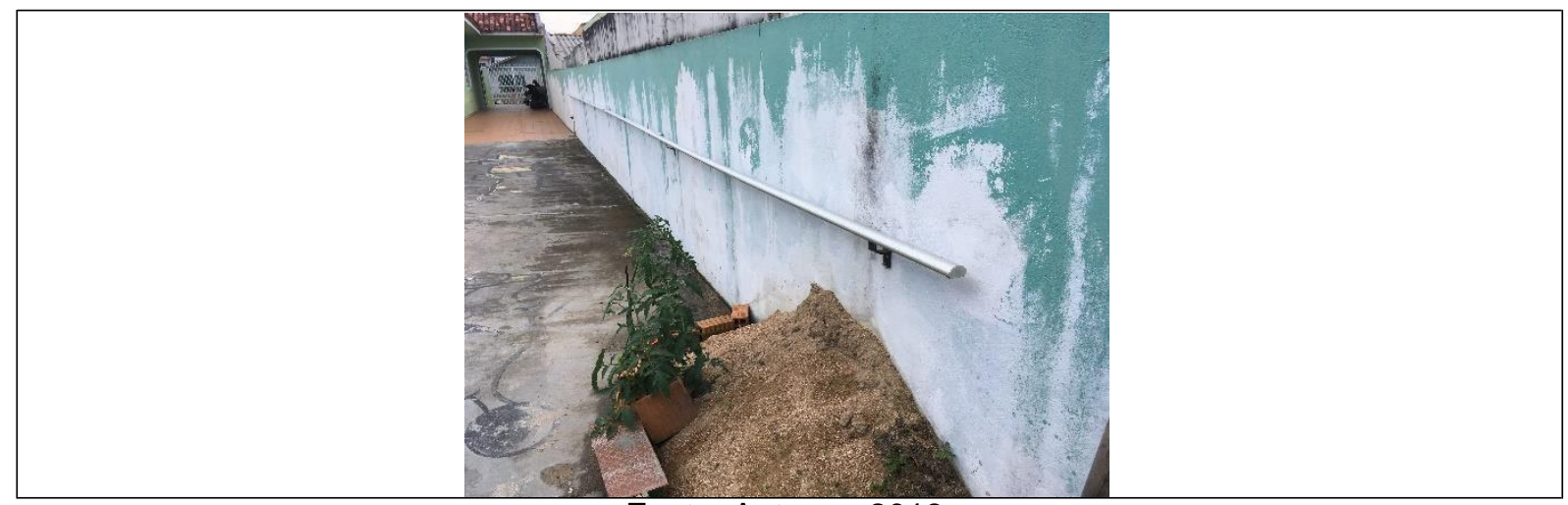

Fonte: Autoras, 2018.

Para solução destes problemas, a NBR 9050/2015 aponta que os materiais de revestimento e acabamento devem ter superfície regular, firme, estável, não trepidante para dispositivos com rodas e antiderrapante, sob qualquer condição (seco ou molhado). Deve-se evitar a utilização de padronagem na superfície do piso que possa causar sensação de insegurança (por exemplo, estampas que pelo contraste de desenho ou cor possam causar a impressão de tridimensionalidade). 
Quadro 3 - Repouso e Higiene pessoal - Suíte.

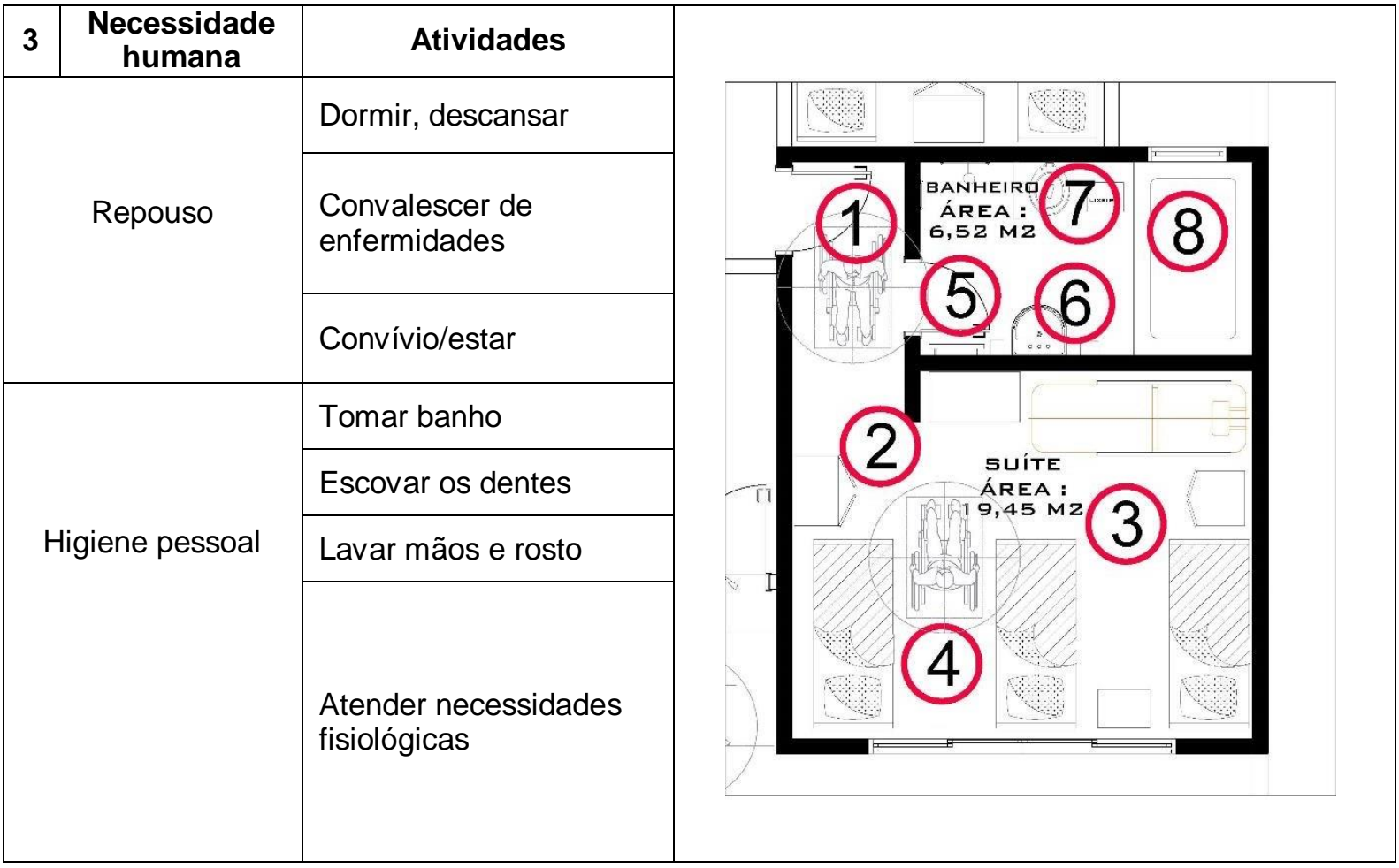

Fonte: Autoras, 2018.

- Problemas 1, 2, 3 e 4: Áreas de circulação e manobra prejudicada no dormitório, tanto para o usuário de cadeira de rodas, quanto para os funcionários. A NBR 9050/2015 define como medida mínima para manobra com deslocamento a dimensão de 1,20m. Sendo assim, constatou-se que as dimensões dos espaços de circulação estão comprometidas pela situação de imóvel alugado e assim adaptado ao uso, agravado pela quantidade excessiva de mobiliário. Observa-se que o acesso à janela também se faz prejudicado (Figura 6).

Figura 6 - Área de circulação e manobra prejudicada.

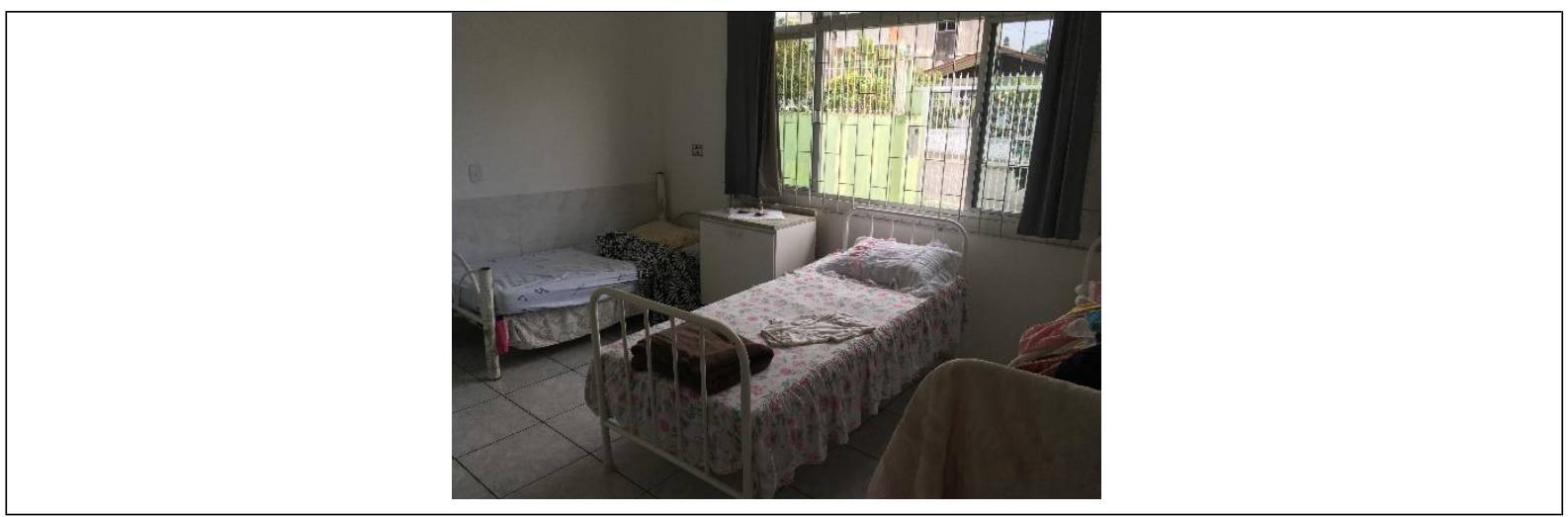

Fonte: Autoras, 2018.

Como solução, recomenda-se a redução do mobiliário e, se necessário, a utilização de armários aéreos com alcance dos funcionários e readequação do layout, permitindo assim 


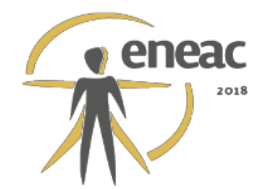

área livre de circulação de 1,20m de acordo com a NBR9050/2015 para manobras e deslocamento adequado, além do convívio no ambiente.

- Problema 5: A porta do banheiro abre para o lado interno do sanitário, quando o recomendado pela norma é que tenha abertura para o lado externo e possuir puxador horizontal no lado interno do ambiente (Figura 7).

- Problema 6: A existência de lavatório com coluna impede a aproximação da cadeira de rodas, o que dificulta a realização de atividades como escovar os dentes e lavar as mãos (Figura 7).

Figura 7 - Lavatório com coluna.

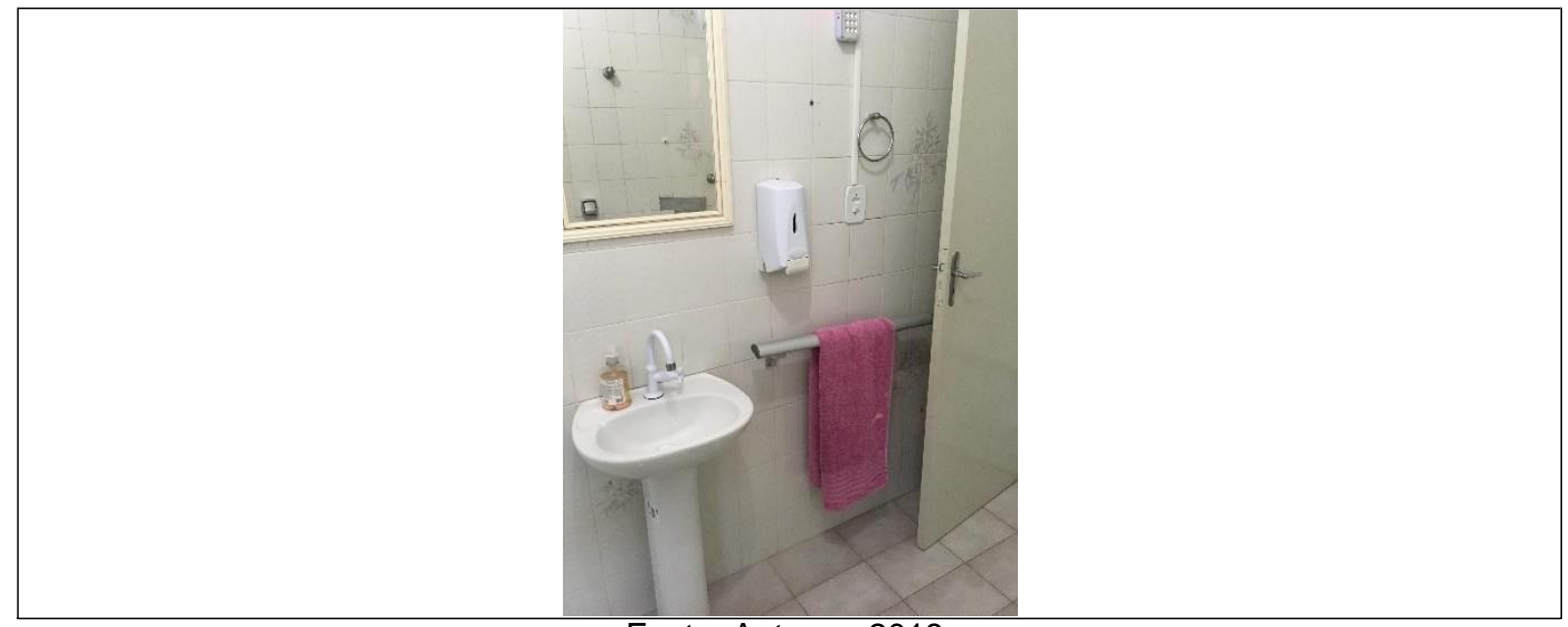

Fonte: Autoras, 2018.

Indica-se, de acordo com a NBR9050/2015, utilização de lavatório sem coluna ou com coluna suspensa sobre tampo, em local que não interfira na área de transferência para a bacia sanitária, permitindo assim espaço para aproximação da cadeira de rodas.

- Problemas 7 e 8: Inexistência de área necessária para garantir a transferência lateral, Norma. Além disto, observa-se a existência de lixeira na pequena área disponível ao lado da bacia sanitária (Figura 8). Outro fator agravante neste espaço, é a presença de uma banheira não acessível. Este mobiliário fixo, além de inutilizado, facilita a ocorrência de acidentes se utilizada pelos demais idosos independentes devido sua altura e inexistência de barras de apoio (Figura 9). 


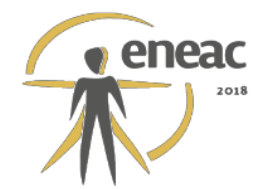

Figura 8 - Área de transferência para bacia sanitária.

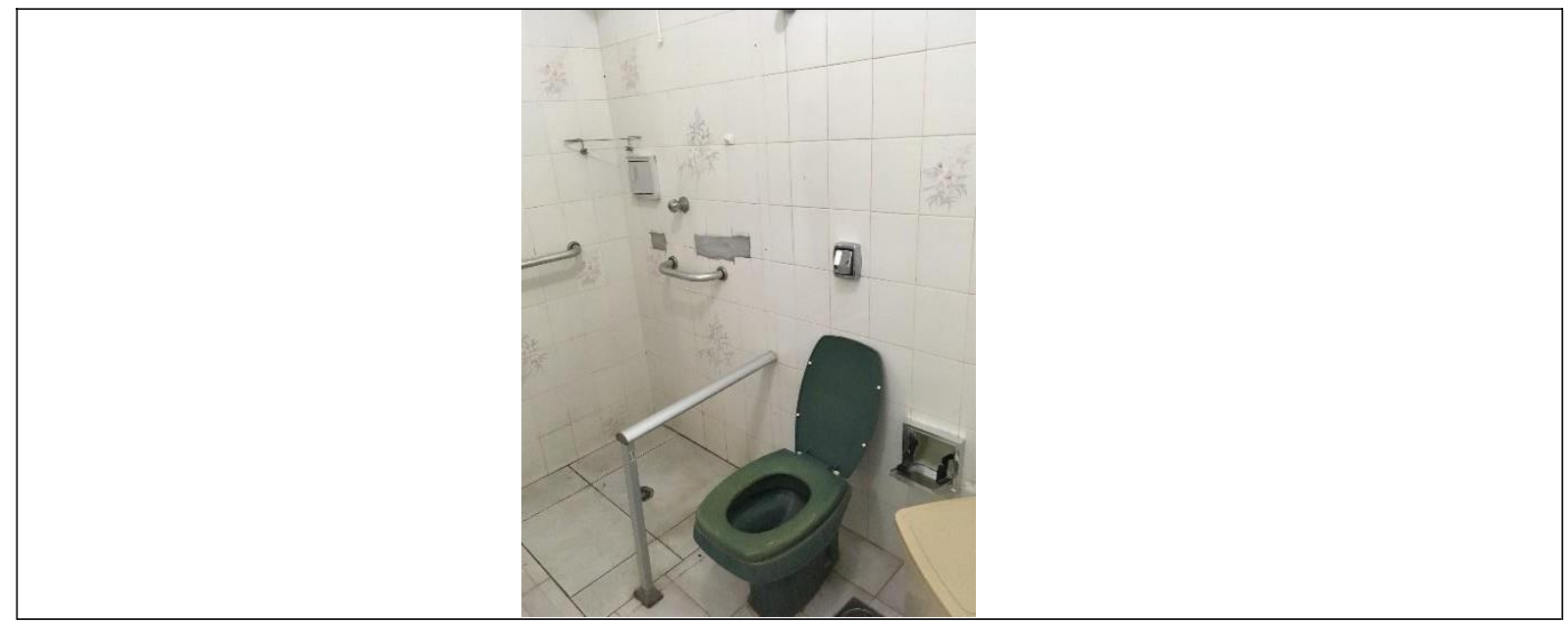

Fonte: Autoras, 2018.

Figura 9 - Chegar até a porta de entrada da ILPI.

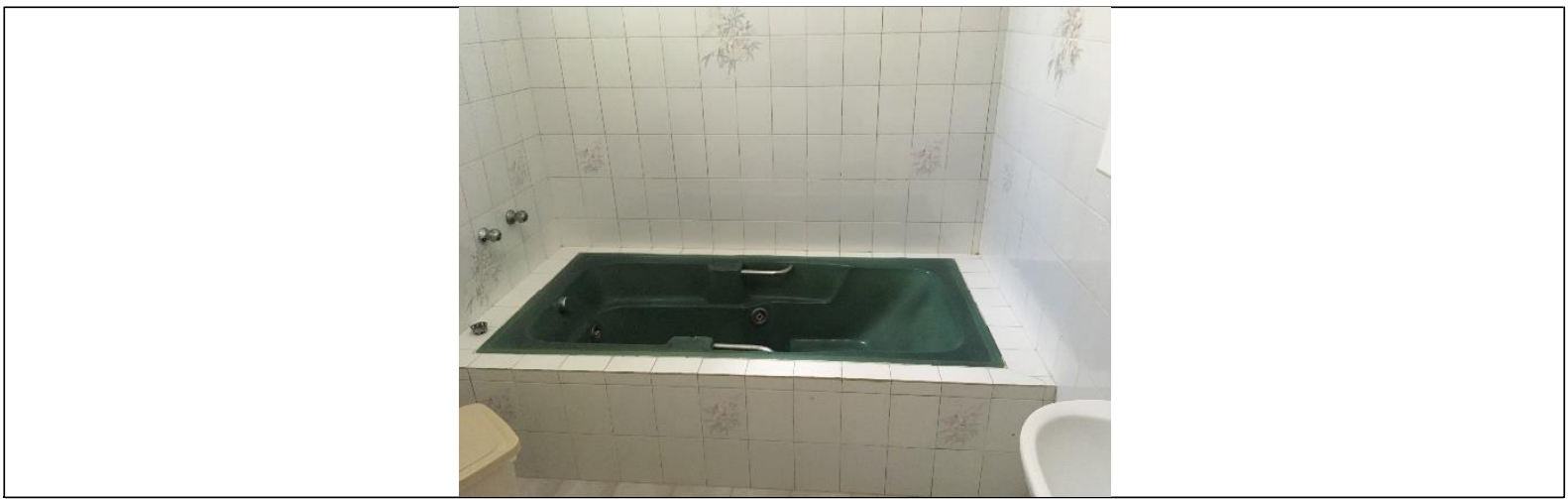

Fonte: Autoras, 2018.

Sugere-se a retirada da banheira não acessível com intuito de ampliar a área de circulação e manobra neste ambiente.

\section{CONSIDERAÇÕES FINAIS}

No início deste artigo deixamos claro que a população idosa no Brasil vem crescendo ao longo dos anos, no entanto, o estudo demonstrou que os projetos arquitetônicos destinados as ILPI necessitam passar por readequações que possibilitem qualidade de vida para estes usuários, uma vez que estas instituições são implantadas em imóveis não destinados a este uso, fator que gera inúmeros problemas.

No decorrer do artigo buscamos responder através das soluções propostas como é possível promover conforto e segurança para o idoso de cadeiras de rodas na ILPI. É claro que estas soluções se limitaram a realidade do caso real estudado, no entanto, o assunto não se esgota neste momento. Conhecer suas necessidades espaciais permite que arquitetos tenham subsídios para propor espaços seriamente comprometidos com o conforto e segurança dos seus usuários. 


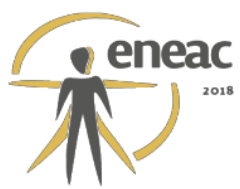

\section{REFERÊNCIAS BIBLIOGRÁFICAS}

ANVISA. Resolução da Diretoria Colegiada, 283, de 26 de setembro de 2005.

ASSOCIAÇÃO BRASILEIRA DE NORMAS TÉCNICAS. NBR 9050: acessibilidade a edificações, mobiliário, espaços e equipamentos urbanos. Rio de Janeiro: ABNT, 2015.

BINS ELY, Vera Helena Moro. A Moradia está Adequada às Necessidades do Idoso? In: IV Worshop de Análise Ergonômica do Trabalho - UFV, jul, 2009.

BRASIL, Casa Civil. Lei no 10.741, de 1ํ de outubro de 2003 - Estatuto do Idoso.

BOGDAN, R. C.; BIKLEN, S. K. Investigação qualitativa em educação: uma introdução à teoria e aos métodos. Porto: Porto, 1994. 336p.

DISCHINGER, Marta; BINS ELY, Vera Helena Moro; PIARDI, Sonia Maria Demeda Groisman.

Promovendo a Acessibilidade nos Edifícios Públicos. Florianópolis: 2009.

DISCHINGER, Marta. Promovendo acessibilidade espacial nos edifícios públicos: Programa de Acessibilidade às Pessoas com Deficiência ou Mobilidade Reduzida nas Edificações de Uso Público / Marta Dischinger, Vera Helena Moro Bins Ely, Sonia Maria Demeda Groisman Piardi. Florianópolis: MPSC, 2012. $161 \mathrm{p}$

HUNT, M. E.The design of supportive environments for older people. In: Congregate Housing for the elderly. Haworth Press, 1991.

MINAYO, Maria Cecília de Souza; DESLANDES, Suely Ferreira; GOMES, Romeu. Pesquisa social: teoria, método e criatividade. 31. ed. Petrópolis: Vozes, 2014. 108p

SILVA, Elvan. Geometria Funcional dos espaços da habitação: contribuição ao estudo da problemática da habitação de interesse social. Porto Alegre, Ed. UFRGS, 1982. 134p.

WHO - WORLD HEALTH ORGANIZATION. International Classification of Functioning, Disability and Health - CIF. World Health Organization. Geneva: 2002. 